\title{
A ampliação das estruturas de controle por meio das tecnologias de informação e comunicação: a onipresença do "pan-óptico eletrônico" no setor bancário
}

The increase of control structures through information and communication technologies: the omnipresence of the "electronic panopticon" in the banking sector

Claudio Lopes Pereira ${ }^{1}$

Lidia Micaela Segre ${ }^{2}$

Rejane Prevot Nascimento ${ }^{3}$

\section{Resumo}

Este artigo analisa, a partir do atual contexto econômico brasileiro, as novas configurações de controle no processo de reestruturação e modernização produtiva dos bancos privados. O setor bancário foi escolhido como objeto de estudo por ter passado por reestruturações a partir da década de 1970, incorporando inovações organizacionais e tecnológicas por meio da adoção de novas tecnologias de informação e comunicação (TICs) que continuam sendo utilizadas. Nesse contexto, o objetivo deste artigo é descrever aspectos do controle do trabalho por meio da intensificação do uso das TICs, bem como analisar a percepção dos trabalhadores sobre esse controle. Essa temática é relevante, tendo em vista que a utilização das TICs nos dias atuais é objeto de estudo fundamental na gestão estratégica das organizações. Entretanto, observa-se que as pesquisas e os trabalhos acadêmicos referentes à adoção das TICs baseiam-se majoritariamente em uma perspectiva funcionalista. Este estudo apresenta um contraponto, na medida em que analisa novas formas de controle sob uma perspectiva crítica, dando ênfase às práticas que ocultam a manipulação da subjetividade, a dominação e o controle dos funcionários. Pretende-se destacar como a estrutura de controle na contemporaneidade é apoiada pelas TICs e sustentada por uma dimensão política e ideológica. Foi realizada uma pesquisa de campo em vários bancos utilizando entrevistas semiestruturadas com gerentes e caixas. Os depoimentos apontam que o controle coercitivo e punitivo anterior deu lugar a um tipo de controle mais sutil, que inclui mecanismos de adesão ativa e cooperante desses profissionais.

Palavras-chave: Controle e trabalho. Tecnologias de informação e comunicação. Setor bancário.

Artigo submetido em 15 de novembro de 2012 e aceito para publicação em 18 de março de 2013.

${ }^{1}$ Mestre em Administração PPGA/UNIGRANRIO; Professor da Universidade Cândido Mendes. Endereço: Rua da Lapa, 86, $9^{\circ}$ andar, Lapa, CEP 20021-180, Rio de Janeiro - RJ, Brasil. E-mail: profclaudiolopes@gmail.com

${ }^{2}$ Doutora em Engenharia de Sistemas COPPE/UFRJ; Professora Emérita do PPGA/UNIGRANRIO. Endereço: Rua da Lapa, 86, $9^{\circ}$ andar, Lapa, CEP 20021-180, Rio de Janeiro - RJ, Brasil. E-mail: lidiamicaelas@gmail.com

${ }^{3}$ Doutora em Engenharia de Produção COPPE/UFRJ; Professora Adjunta do PPGA/UNIGRANRIO. Endereço: Rua da Lapa, 86, $9^{\circ}$ andar, Lapa, CEP 20021-180, Rio de Janeiro - RJ, Brasil. E-mail: rejaneprevot@uol.com.br 


\begin{abstract}
This paper analyzes, through the current Brazilian economic context, the new control setups in the restructuring and productive modernization process of private banks. The banking sector was chosen as a study object because it went through restructurings from the 1970s, incorporating organizational and technological innovations through the adoption of new information and communication technologies (ICTs) which keep being used. In this context, this paper aims to describe aspects of labor control through the increased use of ICTs, as well as to analyze the workers' perception of this control. This set of themes is relevant, taking into account that the use of ICTs today is a crucial study object in the strategic management of organizations. However, one observes that the researches and academic studies related to the adoption of ICTs are largely based on a functionalist perspective. This study presents a counterpoint, in so far as it analyzes new forms of control from a critical perspective, emphasizing the practices which hide the manipulation of subjectivity, domination, and control of employees. One intends to highlight how the control structure is supported by ICTs in contemporary days and sustained by a political and ideological dimension. One conducted a field research in several banks using semi-structured interviews with managers and tellers. The testimonies point out that the previous coercive and punitive control gave rise to a more subtle kind of control, which includes active and cooperative membership mechanisms of these professionals.
\end{abstract}

Keywords: Control and labor. Information and communication technologies. Banking sector.

\title{
Introdução
}

A inserção das tecnologias de informação e comunicação (TICs) nas empresas tem atendido à necessidade de adaptação do sistema produtivo à realidade dos mercados competitivos, que ocorre em escala mundial. Esse novo paradigma caracteriza-se, entre outros aspectos, por sua penetrabilidade em todos os domínios da atividade humana, em especial o das práticas laborais. Segundo Castells (1999, p. 67):

[...] Vivemos um desses raros intervalos na história. Um intervalo cuja característica é a transformação de nossa "cultura material" pelos mecanismos de um novo paradigma tecnológico que se organiza em torno da tecnologia da informação.

No contexto da reorganização da produção se destacam os novos recursos high-tech, como os celulares, os notebooks, as intranets, a internet, os sistemas integrados de gestão e, em especial, o ambiente web, o qual contribui para acesso e produção sem limites de informação. Essa situação gera importantes mudanças nas práticas laborais, nas formas de organização do trabalho e nas relações trabalhistas. Contudo, essas transformações, em especial seus impactos sobre o trabalho, ainda são pouco estudadas, seja no campo dos estudos organizacionais, seja na área de sistemas de informação (MITEV, 2006; HOWCROFT, 2009).

A absorção desse "novo mundo", em especial das novas técnicas, implica a dinamização das formas de atuação das empresas nas quais os trabalhadores deverão adaptar-se aos novos processos produtivos e às novas formas de trabalho que favoreçam o bom desempenho organizacional e, portanto, o lucro (ANTUNES, 2001).

O setor bancário foi um dos mais afetados pela reestruturação tecnológica, principalmente a associada ao uso das TICs e dos sistemas de informação no desenvolvimento de serviços e processos. Jinkings (2006) destaca que, no setor bancário, a intensificação tecnológica se faz cada vez mais presente e que são exigidos trabalhadores mais qualificados, com grande capacidade de gerenciamento e, em especial, que assumam a "multifuncionalidade". Por outro lado, os recursos tecnológicos possibilitam que a atuação dos trabalhadores transcenda os muros das empresas. Para isso, basta integrar-se ao "sistema empresa" por meio dos computadores conectados à internet ou da telefonia móvel.

A reestruturação dos processos produtivos e do trabalho, por causa das inovações organizacionais e da adoção das TICs, expõe os trabalhadores a várias indagações quanto à sua posição, em especial quanto ao 
próprio sentido do trabalho em suas vidas. As novas formas produtivas procuram captar a subjetividade do trabalhador substituindo ordens e regras e fazendo com que este compartilhe os objetivos da empresa. "A adesão aos objetivos é o ponto-chave das relações no trabalho" (PAGÈS et al., 1993, p. 58).

Gorz (1980), em seu seminal estudo sobre as transformações do trabalho na contemporaneidade, já abordava o impacto das inovações microeletrônicas sobre o sentido do trabalho para os indivíduos. Por meio das tecnologias de informação e da própria automação, o capital consegue produzir quantidades cada vez maiores de riqueza com menor emprego do trabalho humano, a ponto desse autor preconizar o fim da categoria trabalho como definido na modernidade. A tese do fim da "centralidade do trabalho" como forma de inserção do homem na estrutura social (GORZ, 1980; OFFE, 1989) e a substituição do trabalho vivo pela microeletrônica, o que tornaria a atividade humana de produção apenas "residual" (GORZ, 1980) dominou os estudos sobre trabalho na década de 1990. É nesse contexto de reconfiguração do papel do trabalho para o homem e de redução da importância do trabalho vivo para as empresas que ocorre a ampliação do poder de barganha das organizações, ampliando-se, paralelamente à introdução das TICs nas empresas, o controle que estas exercem sobre o indivíduo no trabalho. As TICs, assim, ajudam a organizar o trabalho nas empresas, de modo que se torne mais previsível, rotineiro, rígido e controlável.

Para Sennett (2000), as novas estratégias organizacionais conferem uma nova roupagem às práticas dominantes de controle que permeiam as organizações há décadas. A cobrança direta executada pelo "chefe" é substituída, agora, pelas normas expressas na intranet ou no webmail. A liberdade no tempo de execução das tarefas é rastreada pelo número de vezes e horas de acesso ao sistema. A noção de local de trabalho é flexibilizada pelo uso da telefonia móvel e dos computadores conectados ao sistema da empresa por meio da Internet. Assim, as TICs, junto com as mudanças organizacionais, aparecem como um meio eficaz e sutil de controle.

Em particular no setor bancário, foco desta pesquisa, as reestruturações ao longo das décadas de 1980 e 1990 ilustram as ideias apresentadas. Na década de 1980, a adoção das TICs e da terceirização tinha por objetivo a redução dos custos operacionais, eliminando diversos postos de trabalho. Jinkings (2006) destaca que, de aproximadamente 1 milhão de funcionários que compunham o sistema bancário na década de 1980, em 2006 restavam cerca de 400 mil. Na década de 1990, com a criação do atendimento eletrônico, muitos dos serviços prestados nas agências bancárias pelos operadores de caixa passaram a ser realizados diretamente pelos correntistas, por meio de centrais telefônicas, caixas automáticos, internet e sistemas que possibilitam a conexão do computador de casa do cliente ao banco (home banking) ou do trabalho (office banking). Após a otimização de diversos processos e, por conseguinte, a redução dos postos de trabalho, as TICs continuaram a gerar mudanças importantes nas práticas laborais. Na atualidade, os sistemas integrados de gestão, as telecomunicações e seus diversos dispositivos intensificam e controlam a produtividade nesse setor.

Foi escolhido o setor bancário como objeto de estudo diante do alto investimento que esse setor tem realizado em adoção de tecnologia nos últimos anos. De acordo com o relatório anual da Federação Brasileira de Bancos (FEBRABAN, 2010), o investimento das empresas do setor em tecnologia até o ano de 2009 superou a cifra de $\mathrm{R} \$ 19,4$ bilhões.

O objetivo deste estudo é descrever os aspectos do controle do trabalho por meio da intensificação do uso das tecnologias de informação e comunicação (TICs), bem como analisar a percepção dos trabalhadores sobre esse uso. Essa temática é relevante, tendo em vista que a utilização das TICs nos dias atuais é objeto de estudo fundamental na gestão das organizações. O contraponto proposto por esse trabalho é questionar esses novos modelos sob uma perspectiva crítica, dando ênfase à análise das práticas que ocultam a manipulação, à dominação e ao controle dos funcionários em suas ações. Essa perspectiva torna-se particularmente relevante se for considerado que os estudos sobre a temática do controle nas organizações utilizam predominantemente o enfoque funcionalista (MARTINS, 2006). Por outro lado, os estudos sobre TICs e sistemas de informação (SIs) são caracterizados por sua natureza positivista (HOWCROFT, 2009) e por uma preocupação aplicada à resolução dos problemas técnicos decorrentes da implantação da tecnologia (ALVAREZ, 2002), no aumento da competitividade ou na análise do processo de desenvolvimento de sistemas (HOWCROFT, 2009). 
Não obstante, apesar da existência de poucos estudos críticos em SI, diversos autores (ALVAREZ, 2002; MITEV, 2006; STAHL, 2008; HOWCROFT, 2009) ressaltam a importância do desenvolvimento de pesquisas com essa orientação teórico-metodológica. A preocupação dos pesquisadores da área com o desenvolvimento de estudos aplicados pode estar associada, segundo Mitev (2006), à proximidade física nas universidades das áreas de SI da engenharia e das ciências da computação e seu afastamento dos departamentos de Ciências Sociais. Howcroft (2009) atribui a carência de estudos críticos em SI ao limitado conhecimento dos pesquisadores sobre as Ciências Sociais. Some-se a isso o fato de que, mesmo para os pesquisadores do Critical Management Studies (CMS) e do Labour Process Theory, nos estudos organizacionais, as temáticas relacionadas aos impactos da tecnologia sobre o trabalho não são objeto de interesse e investigação (HOWCROFT, 2009). A análise crítica das regras, posições e agendas de pesquisa dos SIs, para Mitev (2006, p. 322, tradução nossa):

Pode impedir a implantação de recursos discursivos de maior dominação, com novos conceitos tais como empoderamento, participação, capital social ou cultural, virtualidade ou flexibilidade, e por meio destas ideias transformando-se em conhecimento gerencial performativo (tradução dos autores).

Do ponto de vista metodológico, esta pesquisa é de natureza qualitativa, utilizando-se dos seguintes procedimentos: pesquisa bibliográfica e pesquisa de campo, com uso de entrevistas semiestruturadas. A pesquisa de campo foi realizada em três grandes bancos privados, nos quais foram entrevistados funcionários que ocupam os cargos de nível gerencial e operacional.

O trabalho está organizado em cinco seções, além desta introdução. Na segunda seção é apresentado o referencial teórico, que contempla análises sobre a adoção das TICs na reorganização do sistema produtivo, os impactos sobre o trabalho e o papel do trabalhador; a ampliação das estruturas de controle por meio das TICs, em particular no setor bancário, utilizando o conceito de "pan-óptico eletrônico" aplicado ao ambiente em rede. Em seguida, são explicitados os procedimentos metodológicos da pesquisa. Na quarta seção são apresentados os dados coletados no estudo realizado no setor bancário, além da análise desses dados. Por fim, são tecidas as conclusões deste estudo.

\section{Revisão da Literatura}

\section{As TICs e a reestruturação do trabalho}

As políticas de reorganização do sistema produtivo geram profundas transformações nos países desenvolvidos e nos emergentes. A internacionalização dos mercados muda os modos de gestão das empresas e, consequentemente, os processos produtivos e as formas de organização do trabalho. $\mathrm{O}$ capitalismo flexível se adapta, criando empresas mais maleáveis, de modo a responder com mais rapidez às mudanças da demanda de consumo. Nessa reestruturação, as novas tecnologias dão mais poder ao "capital flexível", em especial na flexibilização dos modelos de gestão que condicionam os trabalhadores.

As novas tecnologias de informação e comunicação adotadas pelas empresas de capital concentrado contribuíram, no contexto histórico da hegemonia neoliberal, para a implementação de novas estratégias empresariais de internacionalização da produção, impulsionando a mundialização do capital e contribuindo para o desenvolvimento do capitalismo flexível (ALVES, 2007, p. 71).

A adoção de TICs modifica as formas de produção, criando ambientes altamente informatizados e gerando atividades eletrônicas em todas as dimensões do trabalho. Para as empresas, ao informatizar os processos 
administrativos, há redução de tempo e de recursos, possibilitando maior eficiência, produtividade e novos negócios. Esse novo paradigma modificou radicalmente a forma como as empresas são organizadas.

A partir dos anos 1990, os computadores desktop, os notebooks, os sistemas de computadores em rede, os sistemas de telefonia móvel e os sistemas integrados de gestão, entre outros, tornaram-se ferramentas essenciais para a maioria das empresas. O uso dessas ferramentas melhorou significativamente a produtividade, integrando as diversas atividades administrativas, aumentou a comunicação com seus clientes e fornecedores e reconfigurou diversas formas de trabalho, em especial as que transcendem a noção de tempo e espaço no desenvolvimento de suas atribuições. Castells (1999) reforça que a prática da flexibilidade temporal e espacial do trabalho é facilitada pela utilização das TICs, a qual permite que o trabalho seja executado a qualquer tempo e em qualquer lugar, sendo posteriormente disponibilizado, transportado e acumulado na rede.

A introdução das TICs no ambiente de trabalho, assim como em outras esferas da vida humana, desencadeia conflitos decorrentes da relação entre o usuário (o trabalhador, no caso das empresas) e a tecnologia. Jarveenpa e Lang (2005, p. 7, tradução nossa), em estudo sobre a percepção dos usuários da tecnologia móvel em quatro países, assinalam: "Como a tecnologia transcende muitas facetas das vidas dos usuários, as expectativas sobre as capacidades do serviço chocam-se com sua performance na realidade. A experiência dos usuários com a tecnologia é paradoxal" e quanto mais os indivíduos se confrontam com os paradoxos envolvidos no uso da tecnologia, mais significativamente sua experiência com os artefatos tecnológicos é afetada. Para os autores, percepção dos indivíduos sobre o uso da tecnologia depende de fatores situacionais e do contexto no qual estão inseridos, dentre os quais destaca-se o papel que a tecnologia assume para a organização.

No setor bancário, a incorporação tecnológica no processo de produção foi evidenciada por meio da automação no início dos anos 1970, que, nesse primeiro momento, abrangia a administração das operações de retaguarda dos bancos. Posteriormente, o foco passou a recair sobre a inovação dos serviços ao cliente, por meio do uso de sistemas informatizados, com os caixas eletrônicos, as centrais telefônicas, e sobre a diferenciação de produtos e serviços.

O foco atual do setor bancário gira em torno da busca pela "excelência" do atendimento como forma de diferenciação mercadológica. Os avanços tecnológicos contribuíram bastante na implementação de sistemas inteligentes para a definição das estratégias gerenciais do banco que possibilitam criar serviços e produtos personalizados.

A inserção das TICs no setor bancário, em especial dos caixas eletrônicos e do home banking, possibilitou a eliminação de diversos postos de trabalho, já que os clientes passaram a fazer operações por meio desses dispositivos. Posteriormente, as TICs, especificamente os sistemas integrados em rede, possibilitaram a otimização e integração de processos nas agências, proporcionando aos funcionários tempo para atender às especificidades da clientela. Nesse contexto, redefine-se o papel profissional do bancário, exigindo-se desse trabalhador um perfil multifuncional, com habilidade para a venda de produtos (seguros, aplicações etc.) e para a identificação do perfil de cada cliente, a fim de atendê-lo de acordo com suas necessidades e características. Ou seja, o funcionário do setor bancário se transforma em um agente de resultados. "Redefine-se a identidade profissional do bancário alocado nas agências, postos e centrais de atendimento, que se converte em bancário vendedor" (JINKINGS, 2006, p. 194). Nesse contexto, observa-se que as TICs exercem, cada vez mais, maiores impactos sobre as atividades do setor bancário, sendo este, hoje, um dos mais informatizados do país.

\section{0 trabalhador nesse novo contexto}

Como destacado, a partir da necessidade das empresas de adaptação a esse contexto, instaura-se um novo perfil de trabalhador, polivalente e multifuncional. Esse trabalhador deve ter a capacidade de ser "proativo" 
(segundo o discurso empresarial), trabalhar em diversas "máquinas" e funções diferentes, independentemente de estar ou não dentro da empresa. Essa polivalência, de acordo com Alves (2007), Antunes (2001), Antunes e Braga (2009), Jinkings (2002) e Sennett (2000), corresponde a um tipo de perfil de qualificação humana caracterizado pela capacidade do trabalhador mostrar-se funcionalmente "flexível".

Além da flexibilidade que passa a ser demandada, o trabalhador bancário passa a ter necessidade de qualificação contínua. "Quanto mais ampla e profunda a difusão da tecnologia da informação avançada em fábricas e escritórios, maior a necessidade de um trabalhador instruído" (CASTELLS, 1999, p. 306). É preciso manter-se sempre atualizado, reciclar-se e buscar novos conhecimentos para reestruturar e criar soluções que se adequem às necessidades produtivas do capital. Nesse contexto, Berardi (2005, p. 41) também chama a atenção para o perfil desse novo trabalhador:

[...] enquanto o trabalhador industrial colocava no serviço assalariado suas energias mecânicas, segundo um modelo repetitivo, despersonalizado, o trabalhador high-tech empenha na produção sua competência singular, suas energias comunicativas, inovadoras, criativas, em suma, o melhor de suas capacidades intelectuais.

Além de manter-se constantemente atualizado, outra característica fundamental necessária à sobrevivência do trabalhador nesse cenário é a rapidez de resposta ao imprevisto nas tomadas de decisões, ou seja, adaptarse aos imperativos da velocidade e da flexibilidade impostos pelo capital. Bauman (2001) usa o aspecto tempo/espaço, entre outros, para denominar a "modernidade líquida", termo com o qual define o contexto da contemporaneidade. O termo associa-se à metáfora da "fluidez" (qualidade de líquidos e gases) como processo de não fixação no espaço e por não se prender ao tempo. Para adaptar-se a esse contexto, são necessários sujeitos cujas principais características são: a leveza, a mobilidade, a inconstância e a rapidez de movimentos. A mobilidade, corpórea ou não, que é exigida dos trabalhadores, associa-se à lógica da velocidade. Tal fluidez e maleabilidade possibilitam, ainda, integrar esses trabalhadores a diversos ambientes e estruturas. $\mathrm{O}$ ambiente em rede integrado por diversos dispositivos e sistemas facilita a multifuncionalidade exigida desse trabalhador.

Entretanto, a multifuncionalidade vai além da capacidade de operar diversos dispositivos e responder às decisões com maior velocidade na empresa. Essa multifuncionalidade transcende e invade os aspectos tempo/espaço. As TICs acopladas à vida pessoal do trabalhador, em especial os dispositivos portáteis, como o celular e o notebook, possibilitam e exigem que ele seja, ao mesmo tempo, "trabalhador-pai/mãe", "trabalhador-universitário" etc. O ser social e o ser profissional se misturam. Nesse contexto, o "bancáriovendedor", como destaca Jinkings (2002, p. 179), ao realizar seu trabalho, coloca-se à inteira disposição, pois "deverá estar capacitado ao atendimento integral ao cliente". Essa disponibilidade é viabilizada por um "cartão de visita" com e-mail, telefone do banco/ramal e o celular (coorporativo ou não) para entrar em contato a qualquer hora e, assim, poder atender e satisfazer às necessidades do cliente.

Para o trabalhador contemporâneo, a separação de casa, trabalho, escola e lazer fica muito difícil, já que o trabalho na era das TICs invade outras esferas. Para Sennett (2000, p. 53): "As práticas de flexibilidade, porém, concentram-se mais nas forças que dobram as pessoas". Observa-se, nesse sentido, que as mudanças na organização do trabalho pela adoção das TICs intensificam as práticas laborais, acarretando alterações nas condições sociais de sua existência.

\section{A ampliação das estruturas de controle por meio das TICs}

Ao longo dos últimos quarenta anos, as grandes empresas sofreram mudanças profundas. Surgiram novos sistemas produtivos, a partir dos quais a produção em massa deu lugar à produção flexível, as estruturas verticais mudaram a empresa horizontal, as estruturas rígidas e hierarquizadas foram substituídas pelo trabalho em equipe etc. Nesse contexto, os processos organizacionais tornaram-se mais dependentes da 
tecnologia. Na Revolução Industrial, o ápice tecnológico era mecânico e impunha ao trabalhador determinado ritmo de trabalho. $\mathrm{Na}$ atualidade, os processos produtivos dependem da informática, das telecomunicações e da sua integração (TICs), sendo esta fundamental para o tratamento da informação. Porém, simultaneamente ao processo de aperfeiçoamento desses recursos tecnológicos, surge a necessidade de um perfil mais qualificado para o funcionário que faz uso dessas tecnologias. Pode-se observar que o atual modelo de produção com base nos saberes (competências e habilidades) e nas TICs elevou significativamente a produtividade dos bancos e, consequentemente, seus lucros.

Martins (2006), em uma abordagem do controle sob a perspectiva crítico-marxista, em particular sobre o trabalho de Braverman (1987), ressalta que, desde a sua origem, o verbo "gerenciar" está associado a uma conotação negativa, ligada "à opressão ou à alienação do trabalhador" (MARTINS, 2006, p. 7). As estruturas de controle evoluíram, abrangendo os segmentos da gestão da qualidade total, da gestão de pessoas e, em especial, o uso de tecnologias. De acordo com Faria (2004), três fases destacam-se nesse contexto evolutivo. A primeira fase, denominada pelo autor "simples", reforça os aspectos da divisão técnica do trabalho; na segunda fase, a expandida, o enfoque principal recai sobre a função da produção (relação tempo e movimento) e, na terceira fase, a sofisticada, a ênfase recai, principalmente, sobre a subjetividade dos trabalhadores. Já Carvalho (1999) define que o controle nas organizações ocorre de acordo com a seguinte tipologia: controle direto mediante a imposição de ordens e a vigilância expressa; controle estrutural, composto pelo aparato formal da organização, e o controle difuso, sendo este, para o autor, o de mais difícil entendimento, pois se encontra permeado nos aparatos culturais da tomada de decisão da organização.

Na década de 1980, Braverman (1987) já identificava o poder na ampliação do controle que as tecnologias traziam à estrutura produtiva capitalista. A tecnologia predominante dessa época era constituída pelas máquinas de automação. Na transição da produção automatizada para a produção informatizada baseada nas TICs (integração da informática com as telecomunicações), a visão de Braverman (1987) se mantém cada vez mais presente e atual. Os sistemas integrados de gestão, o celular corporativo acoplado à internet, dentre outras tecnologias, possibilitam um controle maior pela empresa e o aumento da produtividade.

Na década de 1990, estudos acadêmicos corroboravam a noção de que as TICs fortaleciam e ampliavam as estruturas burocráticas de controle. Zuboff (1994) define que informatizar é usar a tecnologia de forma mais poderosa do que em um processo de automatização. Ao identificar uma diferença fundamental entre automatizar e informatizar, a autora chama a atenção para o fato de que as TICs contribuem para automatizar as atividades operacionais de controle, reforçando que a informatização aumenta a compreensão das tarefas e procedimentos executados na empresa. Ou seja, o processo de informatização pode ser entendido como o de fazer uso inteligente das TICs, para gerar novas informações que possibilitem condições para se definir políticas gerenciais de acordo com a demanda e o contexto de mercado. Dessa forma, pode-se definir, por exemplo, estratégias competitivas que possibilitem a identificação de perfis dos clientes para a criação de novos produtos e serviços.

Essa forma de uso das TICs amplia o controle, em particular sobre os aspectos cognitivos dos funcionários, haja vista que o processo de informatização exige uma maior compreensão das tarefas e dos procedimentos executados na empresa. Siqueira (2009, p. 49), referindo-se ao controle e à sua ampliação nas empresas, afirma que: "o indivíduo depara-se com novas técnicas e ferramentas de gestão, consolidadas em modelos, que trazem em seu escopo não apenas o controle sobre o corpo do indivíduo, mas de seu intelecto e de seu psiquismo".

Com o avanço das telecomunicações, em particular o advento da internet, os sistemas integrados de gestão, acoplados aos diversos dispositivos portáteis, representam a mais nova estrutura capitalista de produção. Harvey (2010) chama essa forma de produção de "acumulação flexível", na qual se adotam novos padrões de tecnologias flexíveis, exigindo novas qualificações dos funcionários. Essas mudanças são consideradas necessárias para obtenção e manutenção da competitividade no mundo globalizado e são baseadas no uso das TICs. Por outro lado, esse contexto requer reconfigurações e o aperfeiçoamento das estruturas produtivas, em particular a adoção de controles adequados à reprodução ampliada e à mundialização do capital. Sobre esse 
contexto de globalização e flexibilização, Dourado e Carvalho (2006, p. 10) assinalam que: "É preciso reconhecer que a busca pela flexibilidade e a repulsa à rotina burocrática produziram novas estruturas de poder e de controle, em vez de criarem condições de libertação dos homens".

Jarveenpa e Lang (2005) apontam, dentre os paradoxos que emergem da relação entre o indivíduo e as tecnologias, especialmente as tecnologias móveis, o paradoxo entre empoderamento/escravização. Esse paradoxo reside no sentimento de empoderamento proporcionado pela conectividade permanente e, ao mesmo tempo, da impossibilidade de afastar-se, de permanecer distante daqueles com quem o indivíduo não quer contato. Em outras palavras, o conflito se instala quando há a percepção do poder que a tecnologia pode propiciar de controle externo sobre o indivíduo. Ao longo de sua pesquisa os autores observaram, ainda, que esse controle é mais amplo no local de trabalho:

O local de trabalho é uma outra área onde o paradoxo empoderamento/escravidão se manifesta regularmente. Muitos profissionais deram boas-vindas à introdução das tecnologias móveis em suas empresas. Eles valorizaram o incremento da produtividade, a maior flexibilidade e as formas mais eficientes de coordenar pessoas e tarefas. Contudo, as mesmas ferramentas que os empoderaram de diferentes formas em seu trabalho, também levaram embora liberdades que por eles eram prezadas. Além de "menos tempo pessoal", os participantes do estudo citam frequentemente um aumento da pressão no trabalho, monitoramento e supervisão mais próximos e incapacidade de separar e manter distância do trabalho. Os participantes expressaram desagrado em ter que desempenhar múltiplos papéis durante todo o tempo, especialmente tendo que alternar constantemente os papéis entre a família e o trabalho (JARVEENPA e LANG, 2005, tradução nossa).

O paradoxo empoderamento/escravidão se soma ao sentimento de exclusão e "perda", à angústia por não estar conectado. Essa angústia está ligada à cobrança externa quando o indivíduo não está acessível e ao não atendimento de alguma demanda. Tal sentimento impõe ao indivíduo um autocontrole que extrapola os limites do ambiente de trabalho, misturando-se aí o tempo e espaço da família, lazer e trabalho. Identifica-se, nesse contexto, que o controle toma grandes proporções sobre o tempo e o espaço desses funcionários.

\section{O pan-óptico eletrônico}

O capitalismo, na tentativa de manter a ordem e o lucro, apropria-se da estrutura pan-óptica de Bentham (1789), adaptando-a por meio das TICs, em especial da grande rede de computadores, a internet nos dias atuais. A estrutura pan-óptica idealizada por Bentham corresponde a uma composição arquitetônica de cunho coercitivo e disciplinatório que possibilita a observação total e integral por parte do poder disciplinar da vida de um indivíduo. Esse modelo ganhou notoriedade a partir das pesquisas de Foucault, na década de 1970, quando estudava as origens da medicina clínica, em especial a arquitetura hospitalar da segunda metade do século XVIII, época na qual essas instituições passavam por grandes reformas em suas estruturas. No entanto, a estrutura pan-óptica ganhou maior destaque a partir da publicação do livro Vigiar e punir, em 1975, no qual Foucault desenvolve uma análise aprofundada da história da prisão moderna e do poder disciplinar que nela se manifesta de modo exemplar.

De acordo com Foucault (2004), na segunda metade do século XVIII um medo assombrou a Europa. Os diversos lugares, como os castelos, os hospitais e as prisões, suscitaram uma onda de desconfiança e rejeição, pois eram ambientes escuros que impediam a visibilidade das coisas, das pessoas e das verdades. Esses ambientes eram incompatíveis com a nova ordem política e precisavam ser eliminados, dando lugar às transparências e visibilidades. Buscou-se uma estrutura de poder que fosse implementada de modo que o controle pudesse ser exercido pelo simples fato de que as pessoas são vistas por um tipo de olhar imediato, coletivo e anônimo. O pan-óptico estabeleceu uma observação total, uma vigilância integral, sem que se veja seu observador e, principalmente, sem saber o momento em que se está sendo vigiado. No pan-óptico, o 
controle se faz por meio da visibilidade total e permanente dos indivíduos. "O pan-óptico é uma máquina de dissociar o par ver-ser visto: no anel periférico, se é totalmente visto, sem nunca ver; na torre central, vê-se tudo, sem nunca ser visto" (FOUCAULT, 2002, p. 167). Assim, a ordem é garantida, pois o mecanismo de ordem psicológica embutido na estrutura pan-óptica estabelece uma consciência de que mais importante do que vigiar o tempo inteiro é ter consciência de estar sendo vigiado. Logo, a finalidade do pan-óptico não era punir, mas que as pessoas vigiadas tivessem a oportunidade de não cometer nenhuma infração, já que tinham a consciência de que estavam sendo vigiadas.

O autor também ressalta que a estrutura pan-óptica se faz presente nas instituições que dispõem sobre os corpos e a vida dos indivíduos, destacando que o funcionamento do corpo está sujeito a uma utilização econômica do seu funcionamento como força de trabalho. "O corpo só se torna força útil se é ao mesmo tempo corpo produtivo e corpo submisso" (FOUCAULT, 2002, p. 26). É visto um controle sobre o corpo e suas forças. O autor denomina tecnologia política do corpo os mecanismos de sujeição do corpo.

Observa-se que o uso do pan-óptico de Bentham se tornou universal e que continua sendo base dos sistemas disciplinares e, principalmente, do controle regido pelo capital.

Hoje, essa estrutura pan-óptica de controle e vigilância total se renova e expande por meio das TICs. Um dos aspectos centrais da estrutura pan-óptica disciplinar, o confinamento, é substituído pelo controle contínuo por meio do ambiente integrado em rede por diversos dispositivos, no qual se preserva a característica "vê-se tudo, sem nunca ser visto". Na verdade, a essência do confinamento, a nosso ver, permanece, pois a característica onipresente das TICs integra-se na vida dos funcionários quase que como uma prótese, de modo a confiná-lo em qualquer ambiente (casa, trabalho, lazer, entre outros) por meio da rede. Particularmente a internet surge e potencializa a estruturação das empresas em rede, que é a grande estrutura pan-óptica da atualidade. "O homem do controle é antes ondulatório, funcionando em órbita, num feixe contínuo" (DELEUZE, 2010, p. 227).

Assim, constata-se que a estrutura pan-óptica na "sociedade do controle" (DELEUZE, 2010), agora potencializada pelas TICs, continua a instaurar um padrão de "comportamento disciplinar" (FOUCAULT, 2002) por meio desses dispositivos. Produzem-se e reproduzem-se as práticas produtivas do capital, em especial as práticas referentes a "vigiar e punir" (FOUCAULT, 2002).

A "torre" fixa e imóvel que limitava o espaço de observação a uma região de enclausuramento, agora emerge em uma nova situação de soberania, por meio das TICs. A vigilância agora é global, e não importam as distâncias. Onde quer que se esteja e para onde quer que se vá, o "pan-óptico eletrônico" estará presente.

Diante do exposto, é de extrema relevância o seguinte comentário de Deleuze (2010, p. 230): "Os anéis de uma serpente são ainda mais complicados que os buracos de uma toupeira". Observa-se nessa frase que o autor chama implicitamente a atenção para o poder do controle difuso embutido nessa estrutura pan-óptica nos dias atuais por meio das TICs, em especial a internet. Entende-se como "anéis" os nós da grande rede de computadores que interligam os diversos dispositivos, os quais possibilitam uma "vigilância", isto é, um "olhar" onipresente em grande escala e que se adapta a diversos ambientes, já que não necessita de construções específicas. Dessa forma, supera e amplia a vigilância por meio das grandes janelas da torre, limitadas a lugares confinados e restritos, isto é, por meio dos "buracos de uma toupeira". Assim, a dificuldade para entender os "anéis da serpente", ou seja, o "pan-óptico eletrônico", decorre do fato dessa estrutura potencializar a invisibilidade do controle e sua onipresença, dando-nos uma sensação de liberdade, embutida em uma estrutura de trabalho flexível, como se todas as atividades não mais se submetessem a uma permanente vigilância. 


\section{Percurso Metodológico}

A pesquisa realizada é de natureza qualitativa, definida por Stake (2010, p. 20, tradução nossa) como aquela que se baseia na percepção e compreensão humanas, e utiliza normalmente como métodos de estudo a "observação, a entrevista e o exame de artefatos (incluindo documentos)", prescindindo de instrumental matemático ou estatístico para seu desenvolvimento.

Alvesson e Deetz (2000), situam a pesquisa de caráter qualitativo como a abordagem por excelência dos estudos empíricos baseados em perspectivas críticas, embora os autores ressaltem a importância da análise dos fenômenos a partir de múltiplas abordagens, quantitativas ou qualitativas, a fim de assegurar uma visão mais completa da realidade. Vieira (2006), na mesma linha de reflexão, reafirma a relação de complementariedade na construção do conhecimento que existe entre as abordagens qualitativas e quantitativas. O mesmo autor enfatiza, ainda, que: "Por vezes é difícil classificar um método como qualitativo ou quantitativo, uma vez que informações qualitativas podem ser contadas e informações quantitativas podem ser interpretadas" (VIEIRA, 2006, p. 15).

Não obstante, a inexistência de uma preocupação com a generalização das suas conclusões e a impossibilidade de comprovação ou replicação para diferentes realidades, por vezes, de seus resultados, torna a pesquisa qualitativa, sobretudo para os pesquisadores orientados por uma visão positivista, objeto de questionamentos quanto à sua confiabilidade e cientificidade. Nesse sentido, Vieira (2006) observa que, embora possua uma subjetividade maior que a pesquisa quantitativa, dada a sua natureza, a pesquisa qualitativa é fortemente calcada em procedimentos científicos previamente determinados. Para o autor: "A definição explícita das perguntas de pesquisa, dos conceitos e das variáveis, bem como a descrição detalhada dos procedimentos de campo, garantem à pesquisa qualitativa uma certa 'objetivação' do fenômeno estudado permitindo, até mesmo, replicação" (VIEIRA, 2006, p. 18).

A fim de contribuir para a realização de estudos qualitativos bem fundamentados, com rigor científico e de boa qualidade, Vieira (2006) enumera alguns itens que devem ser explicitados na metodologia do estudo: como foram estruturadas as definições constitutiva e operacional da pesquisa, que possibilitam a construção dos instrumentos de coleta de dados e sua posterior análise, a caracterização da pesquisa qualitativa, a descrição do método de estudo utilizado, o corte, o nível e a unidade de análise. Serão utilizados, assim, os itens definidos pelo autor para a apresentação do desenho da pesquisa.

As definições constitutivas dos termos-chave para a pesquisa foram sintetizadas a partir dos do referencial teórico utilizado, tendo por base os conceitos de TICs, flexibilidade, controle, reestruturação e intensificação tecnológica. As definições operacionais da pesquisa foram elaboradas a partir das definições constitutivas, a partir das quais foi construído o instrumento de coleta de dados.

O método utilizado para a pesquisa é o estudo de caso, método caracterizado por Yin (2005) como uma pesquisa empírica que se dedica ao estudo de fenômenos contemporâneos dentro de seu contexto e quando "os limites entre o fenômeno e o contexto não estão claramente definidos" (YIN, 2005, p. 32). Outra característica desse método de pesquisa está no fato de basear-se "em várias fontes de evidências, com dados precisando convergir em um formato de triângulo e, como outro resultado, beneficia-se do desenvolvimento prévio de proposições teóricas para conduzir a coleta e a análise dos dados" (YIN, 2005, p. 33). O corte da pesquisa é seccional, no nível grupal, qual seja, os funcionários de bancos privados brasileiros. A unidade de análise é o trabalho nos bancos privados. O estudo de caso foi realizado por meio de pesquisa de campo em três bancos privados, os quais serão chamados, para fins deste estudo, Banco A, Banco B e Banco C. Foram definidos como sujeitos da pesquisa funcionários dos níveis gerencial e operacional.

Outro aspecto que contribui para a consistência da pesquisa qualitativa é, segundo Vieira (2006), a explicitação da posição epistemológica do pesquisador. Como já indicado na Introdução, esta pesquisa possui orientação crítica, a qual propõe, segundo Alvesson e Deetz (2000, p. 1, tradução nossa): 
[...] Romper com a realidade social em curso a fim de proporcionar impulsos para a libertação de ou resistência ao que domina e conduz a constrangimentos na tomada de decisão humana. Os estudos críticos normalmente colocam um objeto de estudo particular em um amplo contexto cultural, econômico e político, relacionando o fenômeno em foco com as fontes de relações assimétricas na sociedade.

Os autores definem, ainda, três etapas que fazem parte da pesquisa crítica: o momento da interpretação e produção de insights; a desconstrução da realidade, representada pela crítica à exploração, à dominação e à repressão, e a última fase, nem sempre alcançada pelos trabalhos empíricos críticos, que é a etapa de transformação, na qual são indicadas formas alternativas de ação na realidade estudada. Para os autores, o desenvolvimento das duas primeiras etapas é suficiente para caracterizar uma pesquisa crítica (ALVESSON e DEETZ, 2000).

Para a coleta de dados, optou-se pelo método de entrevista semiestruturada. Esse tipo de entrevista possibilita uma abertura e proximidade maior entre entrevistador e entrevistado, o que possibilita ao entrevistador pesquisar assuntos mais complexos e delicados. Isto é, quanto menos estruturada a entrevista, maior será o favorecimento de uma troca mais afetiva entre as duas partes. A espontaneidade nas repostas dos entrevistados e a maior liberdade que estes têm podem fazer surgir questões inesperadas ao entrevistador, que poderão ser de grande utilidade em sua pesquisa (YIN, 2005).

A partir da definição dos sujeitos da pesquisa partiu-se para a preparação do roteiro de entrevista, tendo como base, como mencionado, as definições operacionais da pesquisa. Foram definidos dois roteiros que foram testados por meio de duas entrevistas piloto, a primeira com uma profissional de nível gerencial e a outra com um profissional de nível operacional. As questões do roteiro procuraram verificar as práticas de controle por meio da intensificação do uso das TICs e a percepção dos trabalhadores em relação a esse aspecto. Para isso, o roteiro foi dividido em duas partes. Na primeira parte são identificados os aspectos funcionais do entrevistado, com o objetivo de identificar o cargo exercido, a qualificação, o tempo de serviço no setor, pois estes são dados relevantes para o resultado final da pesquisa. Na segunda parte as perguntas tiveram por objetivo identificar quais são as TICs utilizadas nesse setor, como são realizadas as práticas laborais, relacionando vantagens e desvantagens do uso das TICs, a relação com a política de metas e como ocorre o acompanhamento das atividades, ou seja, o controle pela chefia imediata e pelo banco em geral.

As entrevistas foram gravadas, tendo o consentimento prévio dos entrevistados para gravação e utilização das informações coletadas. Procurou-se preservar a identificação dos entrevistados, bem como a confidencialidade das informações. Após a realização das entrevistas, foi realizada a transcrição, para que os dados pudessem ser analisados.

Para a construção do corpo de dados foram realizadas 10 entrevistas semiestruturadas com funcionários e exfuncionários dos três bancos. O número de funcionários entrevistados por rede bancária ficou distribuído da seguinte forma: 3 entrevistados do Banco A, 2 gerentes de agência e 1 caixa; 3 entrevistados do Banco B, 1 gerente de empresa, 1 gerente de negócios e 1 caixa; e 4 entrevistados do Banco C, 1 gerente voltado para clientes de alto poder aquisitivo, 1 gerente de relacionamento, 1 analista de crédito e 1 caixa

Após a coleta, os dados obtidos em entrevistas foram analisados por meio da análise qualitativa de conteúdo (FLICK, 2009) e interpretados à luz do referencial teórico trabalhado. Com base na revisão da literatura realizada e nas definições constitutivas da pesquisa foram definidas as categorias de análise: percepção do controle associado às TICs, percepção da flexibilidade conferida pelas TICs, uso de celulares e laptops e associação dessas ferramentas com a posição hierárquica do indivíduo. Essas categorias foram agrupadas em uma grade fechada (VERGARA, 2010) e não foram incorporadas novas categorias ao longo da pesquisa de campo. As categorias foram posteriormente confrontadas com o relato dos entrevistados e com os conceitos teóricos, possibilitando uma síntese desse conteúdo e, por fim, a formulação de explicações e interpretações. 


\section{Estudo de Caso no Setor Bancário}

São apresentados nesta seção os dados obtidos por meio das entrevistas semiestruturadas e, posteriormente, a análise e discussão dos resultados. A apresentação dos dados está organizada de acordo com os temas tratados no roteiro e que possibilitam a obtenção da resposta ao problema de pesquisa proposto, a saber: As TICs e seu uso nos bancos; Percepção da flexibilidade proporcionada pelas TICs no trabalho; Acompanhamento das atividades por meio das TICs; Percepção dos funcionários do controle exercido pelas TICs sobre o trabalho.

Do total de entrevistados para esta pesquisa, 5 eram do sexo feminino e 5 do sexo masculino, com idades variando entre 23 e 60 anos. O tempo de trabalho desses entrevistados no setor bancário variava de 3 a 26 anos. Os entrevistados que ocuparam ou ocupam o cargo de Gerente de Agência trabalham, em média, de 10 a 12 horas por dia, enquanto os demais entrevistados de nível gerencial trabalham, em média, de 8 a 9 horas por dia. Já para os entrevistados de nível operacional a carga horária é de 6 horas por dia. Os entrevistados de nível operacional afirmaram, também, que às vezes é necessário fazer horas-extras e que são remunerados por isso.

Em relação ao nível educacional dos entrevistados, 1 declarou não possuir Ensino Superior completo e 1 apenas o Ensino Médio. A grande maioria é formada em Administração (6), sendo que 2 entrevistados declararam possuir duas graduações. Os outros cursos mencionados foram: Gestão Financeira, Marketing e Secretariado.

\section{As TICs e seu uso nos bancos}

O aspecto inicial abordado nas entrevistas estava relacionado à identificação das TICs utilizadas no dia a dia e a relação destas com as tarefas realizadas. Nas respostas obtidas, observou-se uma homogeneização quanto ao tipo e uso. Os entrevistados apontaram um terminal de computador em rede e sistemas próprios do banco, o sistema Outlook, acesso limitado à internet e o uso de centrais telefônicas. Quase todos os entrevistados afirmaram que existe um único sistema que integra todo o banco, no qual a matrícula do funcionário determina o módulo do sistema ao qual pode ter acesso. Suas atividades estavam diretamente relacionadas ao uso do sistema, tendo como foco principal, em ambos os níveis, o atendimento das necessidades do cliente com o máximo de agilidade.

Quanto ao uso da internet, todos os entrevistados afirmaram possuir acesso restrito no ambiente de trabalho. Geralmente é liberado o acesso a sites que fornecem dados específicos dos clientes, como Serasa e Receita Federal. Em alguns casos, nem os sites que fornecem informações sobre o mercado financeiro têm acesso liberado.

Outro aspecto que ficou evidente é a utilização do celular próprio ou corporativo pelo nível gerencial. Os entrevistados destacaram que essa tecnologia é fundamental para o gerenciamento de seu trabalho, em especial no atendimento aos seus clientes. Uma das entrevistadas (Gerente de Negócios) sintetizou: "Às vezes o cliente está com uma dificuldade na rua, tá querendo alguma coisa e eu não estou na agência; o celular ajuda o cliente a me contatar. Isso já faz parte do meu trabalho".

\section{Percepção da flexibilidade proporcionada pelas TICs no trabalho}

Todos os entrevistados evidenciaram que as TICs proporcionam uma grande flexibilidade na realização de suas atribuições, permitindo o desenvolvimento de várias atividades ao mesmo tempo e, em alguns casos, em lugares diferentes. Os entrevistados do nível gerencial destacaram que as TICs flexibilizaram muito o uso da 
informação para as suas atividades, já que os dados são disponibilizados de forma mais integrada e o uso do sistema lhes proporcionou um acesso mais rápido e direto. Para eles, o fato de não depender de terceiros agiliza o tempo de resposta ao cliente.

No nível operacional, a flexibilidade proporcionada pela multifuncionalidade pode ser identificada nos serviços dos caixas do banco de diversas formas. A adoção dos sistemas automatizados no trabalho dos caixas transferiu para esses profissionais algumas das atividades que, até então, eram realizadas por profissionais específicos. Os funcionários do caixa entrevistados relataram que, se o movimento na agência estiver fraco, o gerente da agência solicita uma "colaboração" deles nas atividades administrativas do banco. Um entrevistado esclarece:

Você, para trabalhar no banco, tem que ter uma visão periférica de tudo. Por exemplo, eu sou caixa, preciso saber que tenho que atuar no caixa, na supervisão, enfim, onde eles precisarem. O sistema do banco ajuda muito nesse processo. Tudo está lá. Então, se torna mais fácil você fazer várias coisas, entender as rotinas e se adaptar. Compreende? Qualquer dúvida que você tenha pode ser tirada de imediato pelo help do sistema ou na intranet.

Como se pode observar no depoimento acima, os funcionários já se conscientizaram e institucionalizaram a incorporação das atividades que não possuem relação direta com sua função. Eles consideram que uso das TICs e, consequentemente, as alterações ocorridas no trabalho, como os aspectos da flexibilização em suas atividades e a multifuncionalidade exigida são, na atualidade, parte da dinâmica do próprio setor em geral, de forma que o funcionário precisa adaptar-se, caso contrário, não irá permanecer no emprego.

\section{Acompanhamento das atividades por meio das TICS}

Ao perguntar aos entrevistados "como se dava o acompanhamento de suas atividades e como as TICs entravam nesse contexto?", eles reforçaram que tudo é acompanhado pelo sistema e que inclusive o feedback ocorre por e-mail ou telefone, sendo, na maioria das vezes, acompanhado diretamente pelo chefe em sua própria mesa, como relata uma das entrevistadas (Gerente de Negócios):

O meu gerente acompanha diariamente o meu cockpit. Ele tem diversos relatórios que mostram o meu desempenho e me manda através do Outlook alertas e orientações para que eu melhore. Elogios também. No final do mês, temos uma reunião geral sobre o desempenho da agência. O gerente geral projeta na tela vários relatórios do sistema. Quando algum colega ou setor não está com bom desempenho, há uma reunião a portas fechadas. [...] Ah! Ainda tem a central de atendimento; o banco escolhe um cliente nosso e liga para verificar se ele está satisfeito com o nosso atendimento.

Todos os entrevistados reforçaram repetidas vezes que o que eles precisam fazer depende exclusivamente deles e dos sistemas que são implantados pelo banco para ajudá-los. Nessa fala, verifica-se que, além do controle expresso exercido por ferramentas distintas (via e-mail, Central de Atendimento etc.) que possibilitam uma vigilância total do trabalho, o próprio trabalhador já internalizou esse controle, naturalizando-o. A fim de compreender melhor essa internalização, foi questionado se as TICs promovem um maior autocontrole no trabalho. A maioria dos entrevistados do nível gerencial respondeu de forma negativa, destacando que é necessário um autogerenciamento, característica cada vez mais exigida dos profissionais que atuam no setor bancário. Os entrevistados reforçam que, hoje em dia, tudo o que você precisa saber e fazer em relação ao seu trabalho está no sistema, na intranet e nos treinamentos on-line. Para obter um bom desempenho, é fundamental consultá-los, como destaca uma entrevistada (Gerente de Agência): 
Eu vejo mais como um autogerenciamento. Tenho que ser eficiente naquilo que faço. É fundamental que eu esteja atenta às atividades e aos prazos relacionados ao meu trabalho, e essa tecnologia me ajuda muito nesse autogerenciamento. Tudo que preciso está na rede do banco, então, só me resta consultar e, a partir daí, gerenciar meu trabalho para que os objetivos sejam alcançados. Tenho diversos relatórios que são gerados durante o dia e que me dão base para isso.

Já em relação aos profissionais de nível operacional, fica evidente que as TICs promovem e exigem cada vez mais autocontrole desses profissionais. Os entrevistados reforçam, novamente, que o fato de suas atividades estarem atreladas ao uso dos sistemas exige deles cada vez mais um autocontrole em relação ao cumprimento dos procedimentos e prazos estabelecidos pelo sistema.

\section{Percepção dos funcionários do controle exercido pelas TICs sobre o trabalho}

Todos os entrevistados têm plena consciência de que as TICs favorecem e "muito" o controle e que ele ocorre de forma direta. A maioria das respostas utilizou as seguintes expressões: "Sim, eles sabem exatamente o que a gente está fazendo", "com certeza, o banco monitora tudo o que o funcionário faz", "sim, completamente".

Os gerentes de agência ressaltaram que o banco "tem total informação sobre toda a atividade de uma agência" e afirmaram que esse controle ocorre de forma direta sobre todas as suas atividades, em especial, nas operações que envolvem riscos e que estão relacionadas diretamente com a liberação de ativos. Uma das entrevistadas reforçou que todas as operações realizadas por ela são diretamente analisadas por um "sistema maior" e afirmou:

Tudo que eu digito fica registrado, todos os e-mails que eu envio, todas as operações, principalmente as operações de risco que, na maioria das vezes, são os empréstimos concedidos, são registrados no sistema que vai para um sistema maior e o banco analisa. Eu tenho consciência desse controle direto. Acho que é controle total.

Outro gerente de agência, que vivenciou grande parte do processo de automação/informatização no banco, destacou que a própria hierarquia embutida na estrutura do sistema, em função da senha que estabelece o que pode ser acessado por cada funcionário, já constitui uma forma de controle:

Na minha concepção, é nítido que o banco, ao implementar um sistema, controla tudo, todas as atividades. O próprio acesso ao sistema estabelece uma hierarquia e deixa claro esse controle. A minha senha determina o que posso e o que não posso fazer no sistema, e isso já é uma forma de me controlar. No meu caso, eu tinha acesso a todas as operações que eram realizadas na agência. O que já não acontecia com os demais funcionários. Nós não precisávamos de ninguém dizendo o que tinha que ser utilizado e o que não podia ser utilizado, o próprio sistema já amarrava isso.

O gerente de agência reforçou, ainda, que presenciou muitas demissões após o processo de automação e informatização no setor, pelo fato de que, até então, era fácil "burlar" alguns dos controles realizados manualmente pelo banco, principalmente o controle em relação às metas dos funcionários.

Os profissionais de nível operacional acham que eles são os mais controlados dentro da agência, pois para acessar o terminal é preciso informar a matrícula funcional e que, daí em diante, o banco sabe tudo o que é feito por eles. Um dos entrevistados, caixa no Banco B, destacou que o acesso à conta do cliente também é monitorado e que pode, em alguns, casos, trazer consequências ruins para eles. Ele comentou: 
Tudo que eu faço é controlado e monitorado pelo banco: quantos clientes eu atendi naquele dia, o tempo que eu fiquei parado numa tela, o quanto de produtos e serviços eu vendi naquele dia, Enfim.. Ah! Ainda tem outro aspecto importante e que pode trazer consequências sérias para qualquer caixa. Se a gente entra na sua conta pra ver um determinado saldo ou qualquer coisa parecida e amanhã houver uma fraude, eles sabem que nós acessamos e acabamos sendo vistos pelo banco como um suspeito também. Principalmente se o acesso não estiver relacionado ao atendimento naquele momento ali no guichê, entendeu?

Para outro entrevistado, também caixa, o controle que o banco exerce sobre suas atividades engloba tudo. "Ele controla seu tempo, quando você chega, quando você almoça, o que você faz durante o dia". Ressaltou, ainda, que as atividades realizadas fora do banco também são controladas, referindo-se aos treinamentos online. "Os cursos que você faz são controlados pelo sistema, e se você fizer fora do horário do expediente, melhor ainda". O entrevistado ressaltou que o banco faz um trabalho de conscientização para que esses treinamentos sejam feitos após o horário de expediente.

Esse mesmo entrevistado destacou, ainda, que para ele é fundamental o controle que o banco exerce sobre suas atividades, porque possibilita que a instituição perceba quanto o funcionário se dedica e isso facilita a sua promoção:

Eu gosto de ser controlado. Acho fundamental que o banco veja o que eu fazendo, o quanto estou produzindo. Isso me dá visibilidade, entende? Se ele estabelece as metas e eu cumpro, é sinal de que tenho grandes condições de ser promovido. A minha remuneração variável dá condições do banco perceber o quanto eu tenho feito e o quanto ainda eu posso fazer, entende? No meu caso, eu estou numa escala crescente dentro do banco. Como te falei, estou em fase de transição, saindo de caixa, para supervisor de caixa. Isso foi graças a esse controle. Eles viram que tenho potencial e sou produtivo. O legal é que o reconhecimento vem, entende?

A partir dos depoimentos da maioria dos entrevistados, destaca-se que o monitoramento e controle que o banco exerce por meio das TICs sobre o trabalho é percebido de forma "natural" e "necessário" dentro desse setor.

\section{Análise dos dados}

O objetivo deste artigo foi identificar e analisar a percepção dos funcionários do setor bancário em relação ao controle no trabalho por meio da adoção das TICs. Objetivou-se, ainda, contribuir para a construção de perspectivas mais críticas nos estudos sobre implementação de TICs, optando-se por construir um arcabouço téorico com viés crítico, uma vez que alguns autores abordados assinalam que há predominância dos estudos que reproduzem a perspectiva funcionalista e positivista em relação ao tema abordado.

Os entrevistados evidenciam que a grande vantagem do uso das TICs encontra-se na otimização de processos e na disponibilidade da informação para definição dos perfis dos seus clientes. Assim, o modelo de produção focado na excelência do atendimento ao cliente "flexibiliza", por meio das TICs, as informações de diversas maneiras e otimiza processos oferecendo aos bancos a possibilidade de aumentar sua produtividade. Possibilita definir produtos e serviços diferenciados para seus clientes, bem como que os profissionais envolvidos atinjam as metas e aumentem sua remuneração variável.

Outra característica que ficou evidente nos depoimentos e no referencial teórico, destacado por diversos autores, entre eles Antunes (2001), Antunes e Braga (2009) e Jinkings (2006) é a institucionalização da 
multifuncionalidade exigida. Os entrevistados reforçam que as TICs potencializam esse aspecto. Ser "flexível", "multifuncional" para esses profissionais é uma característica do mercado. Pode-se observar que a percepção positiva que os entrevistados possuem sobre este aspecto está relacionada ao aumento da sua produtividade na medida em que esta reflete diretamente sobre o seu salário. Cabe, nesse contexto, relembrar a citação de Sennett (2000) sobre a flexibilidade, reconhecida pelo autor como a "força que dobra as pessoas". As políticas de gestão (o comprometimento, o autogerenciamento) ajudam a "dobrar" esses profissionais para que sejam mais flexíveis e multifuncionais, de modo a aumentar a produtividade de acordo com as metas estabelecidas. Ainda sob a perspectiva de Sennet (2000), percebe-se que o discurso da eficiência e eficácia promovido pelo mercado ajuda a mascarar o autocontrole exigido. Em especial no nível gerencial, por meio de expressões como "autogerenciamento" e "autogestão", quando, na verdade, ambas têm o mesmo significado que autocontrole. Entretanto, "ideologicamente" esses termos estão relacionados a "ser competente" a "estar apto" para o mercado, enquanto que o "auto" + "controle" é uma expressão que nos remete a pressões, regras e cobranças.

Foi possível identificar nos depoimentos recolhidos as características da ampliação do controle, decorrentes da intensificação tecnológica ocorrida nas últimas décadas no sistema produtivo do setor bancário, citadas pelos autores pesquisados.

As empresas procuram alternativas para adaptar e ampliar as estruturas de controle a cada novo modelo de produção. Essa prática é bastante comum até os dias atuais, e os entrevistados têm plena consciência de que são controlados e, em alguns casos, como observado, manifestam já ter esse controle internalizado (autocontrole). É interessante considerar, a esse respeito, que Carvalho e Vieira (2007) e Faria (2004) destacam que a ênfase na subjetividade dos trabalhadores é a nova forma de controle na empresa moderna. As empresas articulam de forma tão "sutil" a inserção de novos modelos de gestão que conseguem cada vez mais mascarar o controle e a intensificação do aumento da produção e cooptar seus funcionários.

As várias estruturas de controle (direto, estrutural e difuso) definidas por Carvalho (1999) podem ser identificadas nitidamente nos depoimentos. $\mathrm{O}$ controle direto, que está relacionado às políticas de metas, aparece em diversos momentos nas falas dos sujeitos, em particular no relato de uma das entrevistadas, quando ela ressalta que o chefe acompanha diariamente seu cockpit e que no final do mês faz uma reunião a portas fechadas com os funcionários que não tiveram bom desempenho.

$\mathrm{O}$ controle estrutural se relaciona diretamente às TICs. Foi identificado nos depoimentos quando os entrevistados relatam e repetem em diversos itens: "Tudo que precisamos saber está ali na intranet", "o acesso à internet é restrito", "o que eu faço está restrito ao sistema do banco", "as orientações em relação às vendas dos produtos e serviços estão nos cursos on-line", "as informações que eu preciso estão ali", "eu uso, na verdade, os módulos que eles querem, entendeu?". Observam-se nesses depoimentos as características estruturais do setor bancário que "normaliza" e "normatiza" todas as ações, limitando seus "fazeres" a um produto bem-acabado e "formatado" de acordo com os interesses dos bancos. Ou seja, a estrutura dita e impõe as regras. Tal aspecto remete ao questionamento de Mitev (2006, p. 312, tradução nossa), sobre a organização como lócus de conflito, na medida em que "as novas tecnologias são desenhadas e utilizadas para atender a interesses particulares".

Já a eficácia do controle difuso aparece quando esses profissionais mencionam em seus discursos as expressões "cabe a mim, agir da melhor forma possível", "tenho que ser eficiente naquilo que eu faço". Ou seja, é a mudança no seu comportamento que irá determinar os resultados esperados. Esses resultados integram tanto os interesses da organização como os dos funcionários, como destacou um dos entrevistados, caixa no banco A: "Como te falei, estou em fase de transição, saindo de caixa, para supervisor de caixa. Isso foi graças a esse controle. Eles viram que tenho potencial e sou produtivo. O legal é que o reconhecimento vem, entende?".

O gerenciamento e o controle do resultado produtivo nesse setor são realizados e potencializados pelas TICs. Porém, o "controle" é considerado normal, já está internalizado e institucionalizado. 
Entre as novas práticas e na ampliação das estruturas de controle no setor bancário pode-se identificar, no estudo de caso, em diversos itens, a eficiência do "pan-óptico eletrônico" que proporciona visibilidade total e permanente dos indivíduos. Os entrevistados têm consciência de que estão sendo "monitorados" e que qualquer erro será descoberto. Podemos destacar, por exemplo, em um dos relatos, que o empréstimo concedido será avaliado por um sistema maior, assim como no relato que afirma que é melhor para o funcionário fazer os treinamentos exigidos pelo banco fora das instalações. Ou seja, eles têm consciência plena de que são e estão sendo monitorados o tempo todo. Esse contexto representa para os funcionários a proposta embutida no pan-óptico, de que quanto menos e menor for o erro, mais lucrativo será para ambos, sendo melhor "premiar" do que punir.

O setor bancário, cada vez mais, encontra-se imerso em uma política competitiva acirrada e a reestruturação produtiva ocorrida nas últimas décadas, para atender a essa demanda por maior competitividade vincula-se aos processos de automação e informatização. Por um lado, as TICs são utilizadas para um tratamento de massa e de forma padronizada das informações bancárias (automação). Por outro lado, a partir dessas informações são geradas políticas de gerenciamento, são criados produtos e serviços e é dado um atendimento personalizado aos clientes (informatização). As TICs promovem o diferencial nas estratégias competitivas e os investimentos nesses recursos aumentam significativamente a cada ano (ZUBOFF, 1994; JINKINGS, 2006).

É possível verificar, ainda, o paradoxo existente na relação dos entrevistados com as tecnologias por meio das quais são controlados (JARVEENPA e LANG, 2005). Os paradoxos que emergem da relação entre usuário/artefato tecnológico foram explorados na seção Revisão da literatura deste artigo, especificamente o paradoxo empoderamento/escravidão. Tal paradoxo se observa na fala dos indivíduos que exaltam os fatores benéficos para seu trabalho e para seu reconhecimento na empresa embutidos na tecnologia, mas, em paralelo, demonstram insatisfação e desconforto com a vigilância permanente exercida pela empresa (e possibilitada pelas TICs), sintetizada na afirmação "sim, eles sabem exatamente o que a gente está fazendo".

Foi observado que as TICs adotadas no setor bancário favorecem as condições de multifuncionalidade e polivalência institucionalizadas e exigidas dos funcionários, gerando maior flexibilidade nas práticas laborais do bancário, que foi transformado em um "bancário/vendedor" (JINKINGS, 2006, p. 194). Procurou-se explorar, ainda, como o controle se amplia a partir da institucionalização do uso cada vez maior das TICs. Aponta-se que o ambiente em rede é ideal para o trabalho desses profissionais, não só em relação aos aspetos cognitivos, mas, também, em relação ao tempo e espaço, já que as práticas laborais transcendem a agência.

\section{Conclusões}

O aspecto central deste artigo foi compreender os aspectos do controle do trabalho por meio da intensificação do uso das TICs, bem como analisar a percepção dos trabalhadores sobre esse controle. Para atender a esse objetivo, a temática do controle foi explorada a partir de suas diversas estruturas nos modelos de produção que predominaram durante décadas nas empresas. Foi considerado o modelo ainda vigente, denominado por alguns autores modelo "infoprodutivo", e que tem como característica central a "flexibilidade" para atender às demandas do mercado. Destacamos que esses modelos ainda coexistem e que os diversos tipos de controle identificados permeiam a maioria das empresas e, em especial, as do setor bancário. Esses controles têm por objetivo a racionalização do indivíduo diante da produção e, a cada nova estratégia produtiva, a estrutura de controle é reconfigurada. Destaca-se, na atualidade, o controle difuso, considerado o mais difícil de entender, que tem como foco cooptar a subjetividade do indivíduo para dentro da racionalização produtiva. Ou seja, na atualidade, mais do que controlar por meios coercitivos e punitivos, o ideal é obter o consentimento e a legitimação dos funcionários. 
A intensificação tecnológica no setor bancário volta-se ao investimento e à exploração de alternativas mercadológicas direcionadas ao ambiente web, ampliando os negócios, reduzindo custos e aliando-se a uma política de gestão que procura trabalhar a adesão plena dos profissionais. Eles aceitam os sistemas de controle, tendo em vista que serão recompensados a partir da política de remuneração variável estabelecida no setor. A política de metas faz com que os funcionários mantenham-se envolvidos e comprometidos com a dinâmica da produtividade proposta e imposta pelos bancos, mesmo que essa estrutura traga um "desconforto", segundo depoimentos deles. Destacamos a contradição identificada nesses depoimentos, ressaltando que são os funcionários mais antigos que tem essa percepção, já que os mais novos valorizam essa política pelo retorno econômico.

No estudo de caso foi observado que a perspectiva funcionalista em relação ao uso das TICs, associada às práticas gerencialistas, reproduz-se de forma natural e essencial para a maioria dos funcionários que valorizam o uso das TICs sem perceber claramente a intensificação do trabalho, a ampliação do controle e a cooptação da sua subjetividade. Por outro lado, foi possível confirmar o posicionamento crítico abordado a partir do referencial teórico. Conclui-se, então, que, por meio da estrutura do modelo infoprodutivo, que envolve não só aspectos estruturais tecnológicos, mas, também, políticos, humanos e, em especial, ideológicos, as TICs dão ao capital o poder de renovar e ampliar ainda mais o controle sobre a racionalização do trabalho dos funcionários do setor bancário.

Neste estudo é reforçada a percepção de como as TICs no processo produtivo capitalista, em especial no setor bancário, não são implementadas de maneira "neutra". Elas visam a intensificar cada vez mais as práticas laborais e reforçar e ampliar os procedimentos padronizados nos sistemas de produção, bem como utilizar de forma inteligente as informações (informatização). É um processo de produção "flexível" associado a uma lógica econômica na qual as ações desses profissionais precisam estar fundamentadas em padrões de desempenho. Em resposta ao objetivo proposto neste artigo, pode-se concluir que o controle por meio das TICs é percebido pelos funcionários, que estabelecem com as tecnologias no ambiente de trabalho uma relação complexa e conflituosa, na medida em que compreendem que seu papel se confunde entre o controle, nem sempre visto de forma negativa, e a viabilização de dados que auxiliam no desenvolvimento de seu trabalho.

É possível constatar que o discurso ideológico predominante no mercado, qual seja, o de que o mundo globalizado é dinâmico, rápido e, em especial, "flexível", encontra-se inserido de forma natural nos aspectos laborais e sociais dos trabalhadores, conseguindo "minimizar" ou mesmo "ocultar" os efeitos dos instrumentos de manipulação e controle sobre suas vidas. Percebe-se, ainda, que os funcionários não possuem uma visão crítica em relação às suas atividades, especificamente em relação ao uso das TICs, que intensificam cada vez mais o controle sobre suas tarefas e vidas. Pode-se observar o poder com que o sistema capitalista consegue institucionalizar de forma sutil os "mecanismos" que dão força e amplitude à sua estrutura.

Na contemporaneidade, as TICs são cada vez mais necessárias e, para o mundo dos negócios, elas não só aumentam a lucratividade, mas, também, ajudam a manter a ordem, ou seja, a reproduzir e adaptar de forma eficaz a estrutura racional do trabalho, necessária ao capital.

Finalmente, parece-nos importante destacar que o interesse do setor bancário na disponibilização de alternativas mercadológicas baseadas nos serviços on-line, fomentadas pela grande rede de computadores ligada à internet, ainda representa um campo de investigação que pode trazer importantes contribuições. Por exemplo, apontamos como temas a ser aprofundados as características do uso dos "portais" associados ao papel do "bancário-vendedor", na ampliação de sua cartela e segmentação de clientes, no telemarketing realizado pelos gerentes e nas novas tendências em relação ao maior uso de serviços on-line. Ainda nesse contexto, seria interessante pesquisar as futuras reconfigurações do "pan-óptico eletrônico" e as consequências que terão nas vidas dos profissionais do setor bancário. 
Outro aspecto que pode ser alvo de investigação refere-se à continuidade do profissional de "caixa" dentro desse setor. Seria esse profissional, em um futuro próximo, substituído por algum tipo/modelo de "gerente"? Ou seria substituído diretamente pela automação intensificada por meio dos serviços disponibilizados "on-line"?

\section{Referências}

ALVAREZ, R. Confessions of an information worker: a critical analysis of information requirements discourse. Information and Organization, v. 12, p. 85-107, 2002.

ALVESSON, M. e DEETZ, S. Doing Critical Management Research. London: Sage Publications, 2000.

ALVES, G. Dimensões da reestruturação produtiva: ensaios de sociologia do trabalho. Londrina, PR/Bauru, SP: Praxis/Canal 6, 2007.

ANTUNES, R. Os sentidos do trabalho. 4. ed. São Paulo: Boitempo, 2001.

ANTUNES, R.; BRAGA, R. Apresentação. In: ANTUNES, R.; BRAGA, R. (Org.). Infoproletários: degradação real do trabalho virtual. São Paulo: Boitempo, p. 7 - 13, 2009.

BAUMAN, Z. Modernidade líquida. Rio de Janeiro: Zahar, 2001.

BERARDI, F. A fábrica da infelicidade: trabalho cognitivo e crise da new economy. Rio de Janeiro: DP \& A, 2005.

BRAVERMAN, H. Trabalho e capital monopolista: a degradação do trabalho no século XX. 3. ed. Rio de Janeiro: Guanabara, 1987.

CARVALHO, C. A.; VIEIRA, M. M. F. O poder nas organizações. São Paulo: Thomson Learning, 2007.

CARVAlHO, C. A. Poder e Controle. In: VIII Colóquio Internacional sobre Poder Local. Anais do VIII Colóquio Poder Local. Salvador: Editora Gráfica da Bahia, 1999.

CASTELLS, M. A sociedade em rede. São Paulo: Paz e Terra, 1999.

DELEUZE, G. Conversações. 2. ed. São Paulo: Ed, 34, 2010.

DOURADO, D. C. P.; CARVALHO, C. A. Controle do homem no trabalho ou qualidade de vida no trabalho? Cad. EBAPE.BR, v. 4, n. 4, p. 1-15, dez. 2006.

FARIA, J. H. Economia política do poder: as práticas do controle nas organizações. Curitiba: Juruá, 2004. v. 3.

FEDERAÇÃO BRASILEIRA DE BANCOS FEBRABAN. Setor bancário em números. São Paulo: Febraban, 2010. Disponível em: <http://www.febraban.org.br>. Acesso em: 3 out. 2010.

FLICK, U. Introdução à pesquisa qualitativa. Porto Alegre: Ed. Bookman/Artmed, 2009.

FOUCAULT, M. Vigiar e punir: nascimento da prisão. Petrópolis, RJ: Vozes, 2002.

Microfísica do poder. Rio de Janeiro: Graal, 2004.

GORZ, A. Adieux au prolétariat. Au de-là du socialisme. Paris: Galilée, 1980. 
HARVEY, D. Condição pós-moderna. São Paulo: Loyola, 2010.

HOWCROFT, D. Information systems. In: ALVESSON, M.; BRIDGMAN, T. WILLMOTT, H. The Oxford handbook of critical management studies. Oxford: Oxford University Press, p. 392 - 413, 2009.

JARVENPAA, S.L.; LANG K.R. Managing the paradoxes of mobile technology. Information Systems Management, v. 22, n. 4, 2005.

JINKINGS, N. Trabalho e resistência na "fonte misteriosa": os bancários no mundo da eletrônica e do dinheiro. Campinas, SP: Unicamp, 2002.

. A reestruturação do trabalho nos bancos. In: ANTUNES, Ricardo (Org.). Riqueza e miséria do trabalho no Brasil. São Paulo: Boitempo, 2006. p. 189-205.

MARTINS, F. R. Controle: perspectivas de análise na teoria das organizações. Cad. EBAPE.BR, v. 4, n. 1, p. 1-14, mar. 2006.

MITEV, N. N. Postmodernism and criticality in information systems research: what critical management can contribute. Social Science Computer Review, v. 24, n. 3, p. 310 - 325, 2006.

OFFE, C. Trabalho como categoria sociológica fundamental? OFFE, C. Trabalho \& Sociedade: problemas estruturais e perspectivas para o futuro da sociedade do trabalho. Rio de Janeiro: Tempo Brasileiro, 1989. v. 1.

PAGÈS, M. et al. O poder das organizações. São Paulo: Atlas, 1993.

SENNETT, R. A corrosão do caráter: as consequências pessoais do trabalho no novo capitalismo. 4. ed. Rio de Janeiro: Record, 2000.

SIQUEIRA, M. V. Gestão de pessoas e discurso organizacional. 2. ed. Curitiba: Juruá, 2009.

STAHL, B. C. The ethical nature of critical research in information systems. Information Systems Journal, v.18, n. 2, p. 137-163, 2008.

STAKE, R. Qualitative research. Studying how things work. New York: The Guilford Press, 2010.

VERGARA, S. Métodos de pesquisa em administração. 4. ed. São Paulo: Atlas, 2010.

VIEIRA, M. M. F. Por uma boa pesquisa (qualitativa) em administração. In: VIEIRA, M. M. F.; ZOUAIN, D. M. Pesquisa qualitativa em administração. 2. ed. Rio de Janeiro: Ed. FGV, 2006.

YIN, R. K. Estudo de caso. Planejamento e métodos. 3. ed. Porto Alegre: Bookman, 2005.

ZUBOFF, S. Automatizar/informatizar: as duas faces da tecnologia inteligente. RAE, v. 34, n. 6, p. 80-91, nov./dez. 1994. 